\title{
Pleistocene genetic legacy suggests incipient species of Sebastes mentella in the Irminger Sea
}

\author{
MÖ Stefánsson ${ }^{1}$, T Sigurdsson ${ }^{1}$, C Pampoulie ${ }^{1}$, AK Daníelsdóttir ${ }^{1}$, B Thorgilsson ${ }^{1}$, A Ragnarsdóttir ${ }^{1}$, \\ D Gíslason ${ }^{1}$, J Coughlan ${ }^{2}$, TF Cross ${ }^{2}$ and L Bernatchez ${ }^{3}$ \\ ${ }^{1}$ Marine Research Institute, Reykjavik, Iceland; ' ${ }^{2}$ Department of Zoology, Ecology and Plant Science, University College Cork, \\ Lee Maltings, Prospect Row, Cork, Ireland and ' ${ }^{3}$ épartement de Biologie, GIROQ, Université Laval, Ste-Foy, Québec, Canada
}

\begin{abstract}
To investigate a possible speciation event within the redfish (Sebastes mentella) complex in the Irminger Sea, we examined genetics, traditional morphology, geometric morphometrics and meristics of individuals sampled throughout the Sea. Tissue samples from 1901 fish were collected in 1995 and 1996 and from 1999 to 2002, and the fish were genotyped at nine microsatellite loci, two of which were developed for this study. Individual-based genetic analyses showed that two different gene pools exist in the Irminger Sea. Although these groups overlap extensively geographically, they segregate according to depth: those above and below $550 \mathrm{~m}$. This signal of genotype distinction with depth was evident in both the
\end{abstract}

earlier and later sampling. Historical imprints in the genetic data indicated that the redfish in the Irminger Sea are likely to represent a case of an incipient speciation event that began in allopatry during the Pleistocene glaciations followed by secondary contact. Although hybridization was observed between groups, an analysis of traditional and geometric morphometrics and of meristic variables suggested that restricted gene flow between the currently parapatric deepand shallow-mesopelagic incipient species may be maintained by ecological isolation mechanisms.

Heredity (2009) 102, 514-524; doi:10.1038/hdy.2009.10; published online 4 March 2009

Keywords: allopatry; microsatellites; morphology; natural selection; postglacial colonization; Sebastes mentella

\section{Introduction}

The formation of species usually requires the evolution of reproductive isolation between formerly geographicallysegregated populations (Coyne, 1992; Knowlton, 1993). The Pleistocene period is known as a period of intense speciation for a number of biota (Hewitt, 1996; Bernatchez and Wilson, 1998; Ribera and Vogler, 2004; Luchetti et al., 2005). It has been proposed that the fragmentation of the ancestral species geographically range into more than one glacial refuge can result in allopatric speciation, through complete isolation of refugial populations (Hewitt, 1996). Empirical investigations have shown that the Pleistocene glaciations have left an imprint in the genetic composition of many Northern hemisphere species (see Hewitt, 2000 and Bernatchez and Wilson, 1998; for reviews, also Turgeon and Bernatchez, 2001; Gysels et al., 2004a, b; Fraser and Bernatchez, 2005; Pampoulie et al., 2008). As these species ranges expanded out of isolated glacial refugia during the most recent post-glacial warming, secondary contact occurred, which might have led to hybridization and introgression. However, in some cases sufficient differences had evolved between isolated populations during the Pleistocene glaciations (Hewitt, 1996) and reproductive isolation persisted on secondary contact (allopatric speciation; Bernatchez and Dodson, 1990). The evolution of prezygotic and post-zygotic isolation (see Coyne, 1992) could

Correspondence: Dr C Pampoulie, Marine Research Institute, PO Box 1390, Skúlagata 4, IS-101 Reykjavik, Iceland.

E-mail: chrisp@hafro.is

Received 30 December 2008; accepted 5 January 2009; published online 4 March 2009 have occurred as a by-product of the gradual accumulation of neutral genetic differences between populations in the absence of gene flow (Dobzhansky, 1937; Lessios, 1981; Kelly et al., 2006), as a result of adaptation to divergent environments (Schluter, 2001) or from both processes.

Redfish species of the genus Sebastes are ovoviviparous, slow growing fishes that mature sexually at an age between 10 and 15 years. Within the Irminger Sea, two phenotypes of the redfish species Sebastes mentella (Travin, 1951), oceanic and deep-sea types have been described, based on the external morphology (Magnússon and Magnússon, 1995). The occurrence of pelagic redfish in the Irminger Sea has been known since the middle of the twentieth century, (Taaning, 1949) and it has been shown that $S$. mentella inhabits the area throughout the year (Sakharov, 1964; Jones, 1968). The oceanic phenotype was first described by Magnússon (1972) and its geographic distribution extends over the entire Irminger Sea, where it seems to be restricted in the East by oceanographic conditions (mainly temperature) in the Reykjanes ridge area as no oceanic redfish have been observed offshore, south of Iceland (Magnússon and Magnússon, 1995). These two phenotypes have overlapping spatial distributions, but there are differences in the depths at which they occur. The oceanic phenotype is most abundant in the pelagic zone at depths of about $50-400 \mathrm{~m}$ and is most common at depths of $200-350 \mathrm{~m}$, whereas the deep-sea phenotype is most abundant at depths exceeding $600 \mathrm{~m}$ (ICES, 2001). The deep-sea phenotype is generally more common in the north-eastern part of the area, whereas the oceanic phenotype has a more south-western distribution (ICES, 2001). 
Differences exist between the phenotypes in size at maturity. The oceanic type matures around $31 \mathrm{~cm}$ total length, whereas the deep-sea type is around $38 \mathrm{~cm}$ (Magnússon and Magnússon, 1995). Little is known about the location of the mating areas of either phenotype, although an indication can be obtained from catches of mature males in autumn. Although geographical distributions of mature males from the two forms overlap to some extent, the biggest aggregations are discrete, with oceanic males occurring more in the southwest, whereas deep-sea males are more northeastwardly located (ICES, 2005). The main area of larval extrusion (spawning) of the oceanic form is south of $65^{\circ} \mathrm{N}$ and east of $32^{\circ} \mathrm{W}$, and extends south-westwards as far as $52^{\circ} \mathrm{N}$, whereas the deep-sea form mostly spawns closer to the Icelandic shelf. Although spawning areas overlap geographically in the northeast part of the Irminger Sea, deep-sea fish spawn at greater depths (>500 m; Magnússon and Magnússon, 1995).

Earlier genetic studies of Sebastes species in the eastern North Atlantic have focused mainly on species identification, using a variety of molecular markers (for example, Altukhov and Nefyodov, 1968; Nefyodov, 1971; Johnson et al., 1973; Naevdal, 1978; Dushchenko, 1987; Nedreaas and Naevdal, 1989, 1991a,b; Johansen et al., 1993; Nedreaas et al., 1994; Roques et al., 1999a; Pampoulie and Daníelsdóttir, 2008). These studies have shown that interspecific differentiation is generally low in redfish species, whereas both allozyme and microsatellite studies of $S$. mentella indicated limited population differentiation (Dushchenko, 1987; Nedreaas and Naevdal, 1991b; Nedreaas et al., 1994; Roques et al., 2002).

Novikov et al. (2002) suggested that oceanic and deepsea redfish $S$. mentella in the Irminger Sea consisted of a single panmictic population and that the oceanic fish inhabiting the upper layer were shorter and therefore younger than the deep-sea fish. They also argued that genetic differences at $M E P-2^{*}$ between redfish from the two different zones was a result of strong directional selection, which occurred when younger fish moved into deeper waters. They suggested consequently that variation in allele frequencies was the result of 'natural loss and enhanced mortality ...' of younger fish when they increased in age and moved to deeper waters.

In an attempt to further investigate the genetic structure of $S$. mentella in the Irminger Sea, and provide an insight into the evolution of the species, we examined the genetic composition of redfish samples collected from 1999 to 2002, and in 1995 and 1996. The latter were included to test for temporal variation. Sampling was carried out at two distinct depths, to investigate variation between the two groups discussed above. Bayesian statistics as well as conventional genetic analyses were applied to microsatellite data to investigate horizontal and vertical spatial distribution of genotypes within the Irminger Sea. Genetics were supplemented with morphological and meristic investigations to examine the biological significance of any spatial differences detected.

\section{Materials and methods}

\section{Sampling}

Samples were collected within the Irminger Sea using pelagic trawls. Samples that were potentially character- istic of the two pelagic stocks were targeted, above ('shallow-mesopelagic zone') and below ('deep-mesopelagic zone') $550 \mathrm{~m}$. Therefore, grouping of samples was not based a priori on phenotypic information but instead on vertical distribution. Geographical distance of each sample from the southwest tip of the Reykjanes Peninsula, Iceland was also recorded $\left(63^{\circ} 82^{\prime} \mathrm{N}, 22^{\circ} 77^{\prime} \mathrm{W}\right.$; asterisk in Figure 1).

Tissue samples for genetics were taken from 1901 fresh or whole-frozen fish collected at sea in 1999, 2000, 2001 and 2002 (Figure 1; Supplementary Appendix S1, see Supplementary material) and from archived samples from 1995 to 1996. Samples represented individuals caught in the same season or year, at the same depth and at the same location. Specimens for morphological $(n=691)$ and meristic studies $(n=713)$ were collected in 2000, 2001 and 2002 and frozen at sea (Supplementary Appendix S2, see Supplementary material). Eighteen morphometric variables were measured (Figures 2a and b), using landmarks as defined by Saborido-Rey and Nedreaas (2000) (with the exception of the width between opercula (AN)). Coloured pins were located at each landmark and each fish photographed using a digital camera. Two methods were used for calibration: a ruler was included in each photograph and the length of the first dorsal fin was measured using callipers $( \pm 0.02 \mathrm{~mm})$. The latter were also used to estimate the standard length of each individual.

The acronyms and descriptions of the eight meristic characters are given in Supplementary Appendix S3 (see Supplementary material). Codes describe the angle of the third (A3S) and the fifth (A5S) pre-opercular spines (Supplementary Appendix S3, see Supplementary material; Figure 2c). Numbers refer to relative positions of the five spines, starting at the top of the operculum, A5S being closest to the mouth.

\section{Genetic analysis}

Two novel tetranucleotide microsatellite loci were developed for this project: Smen5 (F: TTATGGAACTGTGATA CTGG; R: TAGCCTCGTATTGCATTGAA; repeat motif $(\mathrm{CTAT})_{18}$ ) and Smen10 (F: TGAAAAGTTTGAAAGCT CTG; R: GTCGTGTCGTTTGTGTGAAT; repeat motif $(\text { ATAG })_{16}$ ) Genbank accession numbers EF035461 and EF035462, respectively.

For microsatellite screening, DNA was extracted using phenol-chloroform (Sambrook and Russell, 2001) or Chelex (Walsh et al., 1991). Samples were screened for variation at nine microsatellite loci; five dinucleotides (SEB9, SEB25, SEB33, 5'-Fluor Label, NED; SEB31, 5'-Fluor Label, 6-FAM; SEB45, 5'-Fluor Label, HEX; Roques et al., 1999b); three tetranucleotides (Smen5, 5'Fluor Label, 6-FAM; Smen10, 5'-Fluor Label, HEX; current publication; Sal1, 5'-Fluor Label, 6-FAM; Miller et al., 2000) and one pentanucleotide (Sal3, 5'-Fluor Label, HEX; Miller et al., 2000). Details of PCR protocols are available only on request.

Data analysis: genetic diversity and differentiation

Two Bayesian models were used to estimate the most likely number of populations (K) represented in the samples (STRUCTURE version 2.1, Pritchard et al., 2000; BAPS version 4.13, Corander et al., 2003, 2004). All samples from both sides of the 550-m depth zone in the 


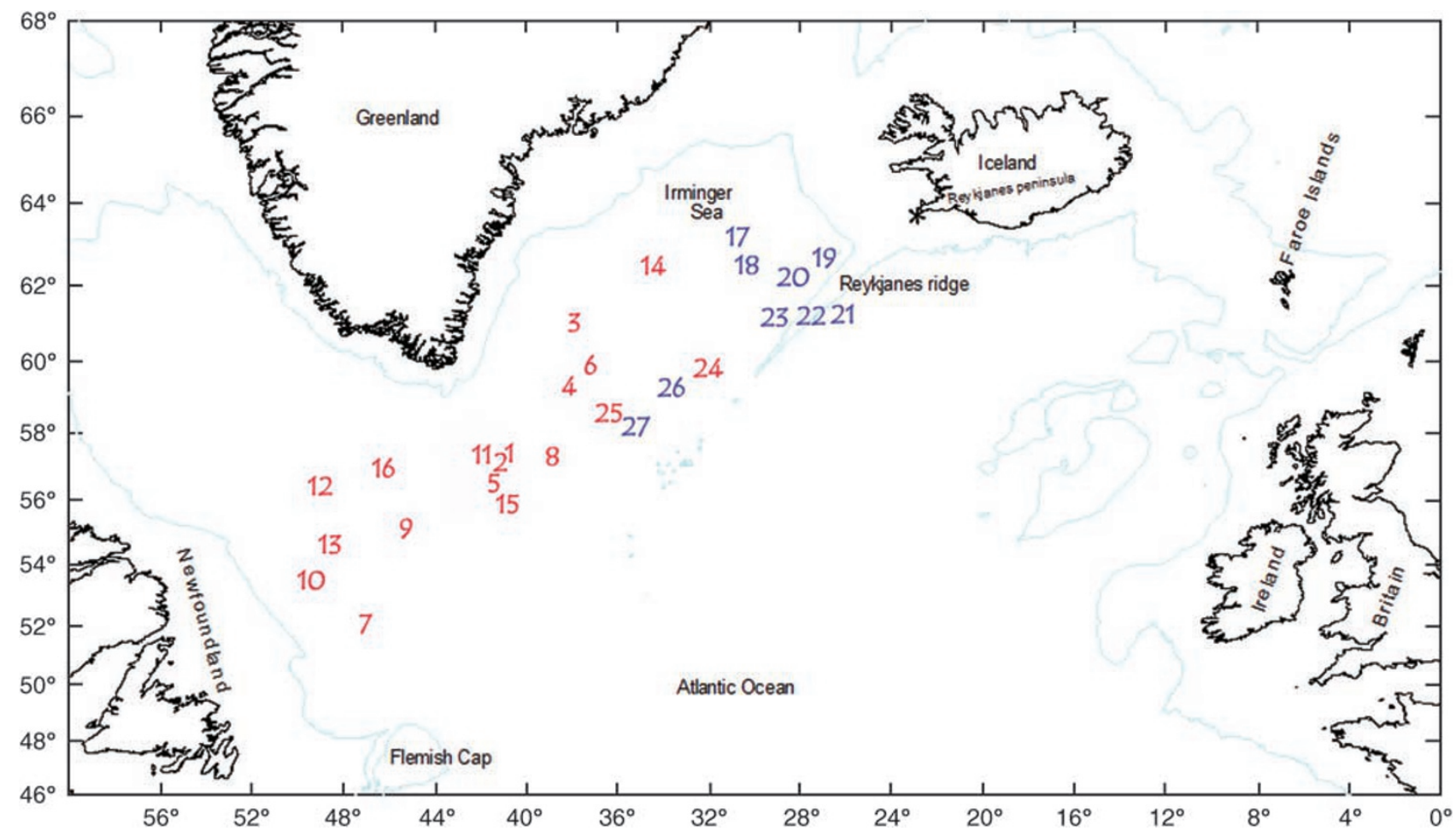

Figure 1 Sample locations of 27 samples of S. mentella from the shallow- (red) and deep- (blue) mesopelagic zones of the Irminger Sea (see Supplementary appendix S1 in Supplementary material for number). The $1000 \mathrm{~m}$ bathymetric contours are indicated (faint green). The asterisk shows the location of the centre of circle (south-west tip of the Reykjanes peninsula, Iceland; $63^{\circ} 82^{\prime} \mathrm{N}, 22^{\circ} 77^{\prime} \mathrm{W}$ ), which was used for calculations of distance. The Irminger Sea stretches from the south-west of Iceland. It is enclosed by Greenland to the west, the Reykjanes ridge to the east, the Denmark Strait to the north and Newfoundland to the south.

Irminger Sea were included in both analyses. The STRUCTURE run consisted of a 500000 burn-in period, then $10^{6}$ iterations for the Markov Chain Monte Carlo simulations, assuming admixture and correlated allele frequencies. Other input parameters were set at default values. The simulations were repeated 20 times for each value of $\mathrm{K}$, from 1 to 12 . To confirm the estimate of $\mathrm{K}$, the ad hoc statistic $\Delta \mathrm{K}$ was calculated according to Evanno et al. (2005). $\mathrm{K}$ is indicated by the mode of the $\Delta \mathrm{K}$ distribution, with the height of the mode being taken as an indicator of the signal strength detected by STRUCTURE. The model was free from any assumptions about population structure within the Irminger Sea. Individual admixture proportions $(q)$ were plotted against depth and distance from the southwest tip of the Reykjanes peninsula. The distribution of $q$ from the two-depth zones was tested using the Mann-Whitney U-nonparametric test (Sokal and Rohlf, 1981).

The program BAPS was used to cluster groups of individuals with the original samples being defined as groups. The program was run using the non-spatial model for genetic discontinuities, and without any $a$ priori assumptions about the spatial location of samples. Thus, population inference was based solely on genotypes. The maximum number of clusters was set at 27, equal to the number of samples. To avoid the risk that the algorithm could assume a local mode, the program was run at different $\mathrm{K}$ values. Individual admixture proportions were calculated based on mixture clustering after 1000 simulations and the distribution of samples between clusters was then evaluated. As for STRUCTURE, no pre-defined clustering was used.
Exact tests were used to test homogeneity of allele (Raymond and Rousset, 1995a) and genotype (Goudet et al., 1996) frequencies across samples using GENEPOP (Raymond and Rousset, 1995b). The same dememorisation number (10000), batch number (100) and iterations per batch (10000) were used for all Markov Chain tests. FSTAT (Goudet, 1995) was used to estimate overall and pairwise $F_{\mathrm{ST}}$ values (Weir and Cockerham, 1984); to test for fit to Hardy-Weinberg proportions (HWE); to test for linkage disequilibrium between loci and to compare allelic richness $(r)$. In all cases 15000 permutations were used for significance testing. Multidimensional scaling analysis, based on pairwise $F_{\mathrm{ST}}$ values and undertaken in R (Ross and Gentleman, 1996), was used to visualize relationship among samples.

A hierarchical analysis of molecular variance (AMOVA) utilizing ARLEQUIN version 3.01 (Excoffier et al., 2005) was undertaken to examine depth and temporal dimensions within each depth zone. The statistics associated with these components were tested using a nonparametric approach and also estimated using $F$-statistics (infinite allele model) based on variance in allele frequencies. $R$-statistics (stepwise mutation model) based on allele sizes were also applied, to determine whether mutations had effected the partition of variance components (Excoffier et al., 1992).

Data analysis: evolutionary history and time of divergence To examine evolutionary history, we compared the global variance in allelic identity $\left(F_{\mathrm{ST}}\right.$ and $\left.\theta_{\mathrm{ST}}\right)$ and allelic size $\left(R_{\mathrm{ST}}\right)$ between depth zones (samples pooled). Allele sizes observed at each locus were randomly permuted among 
a
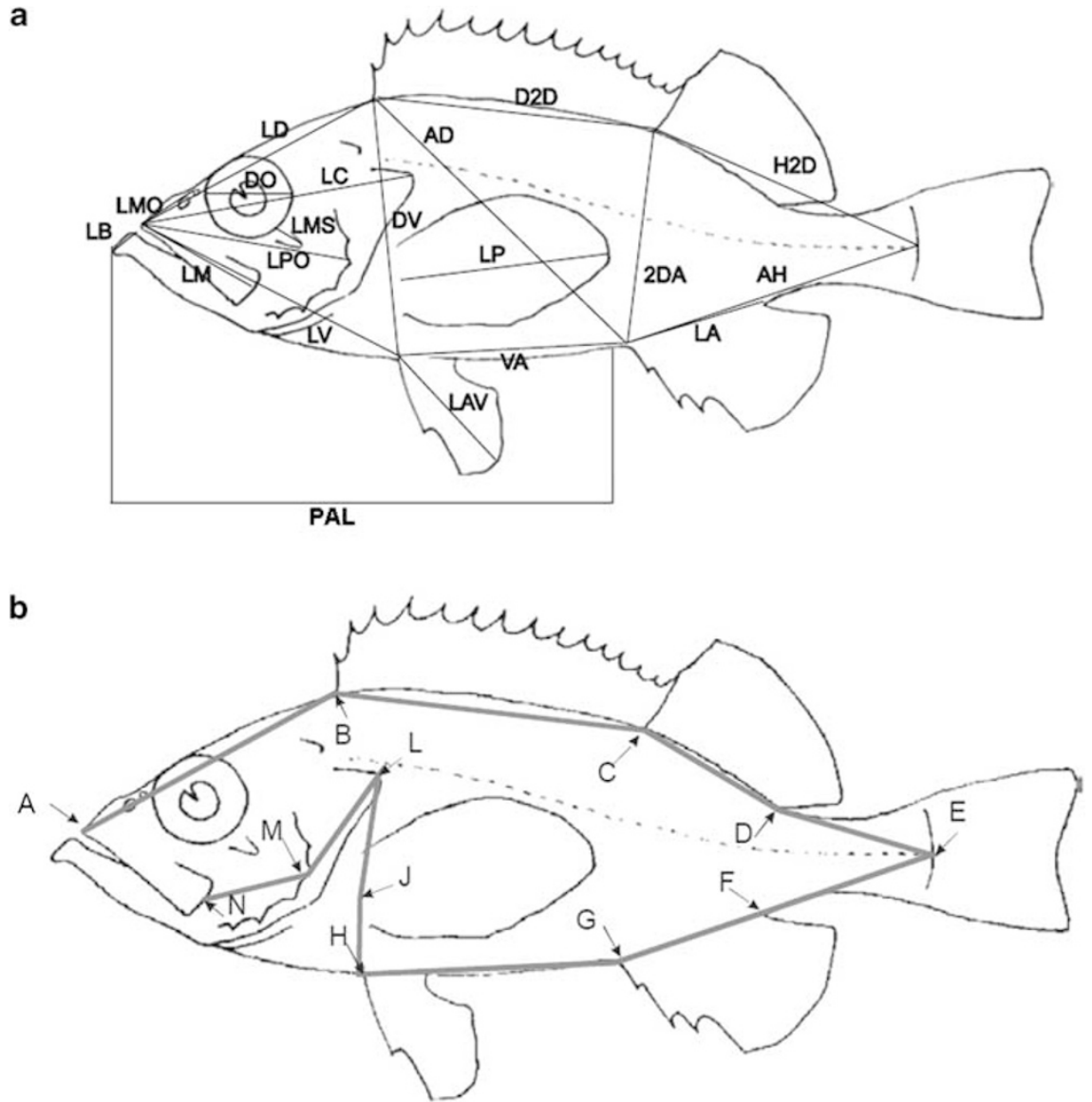

C

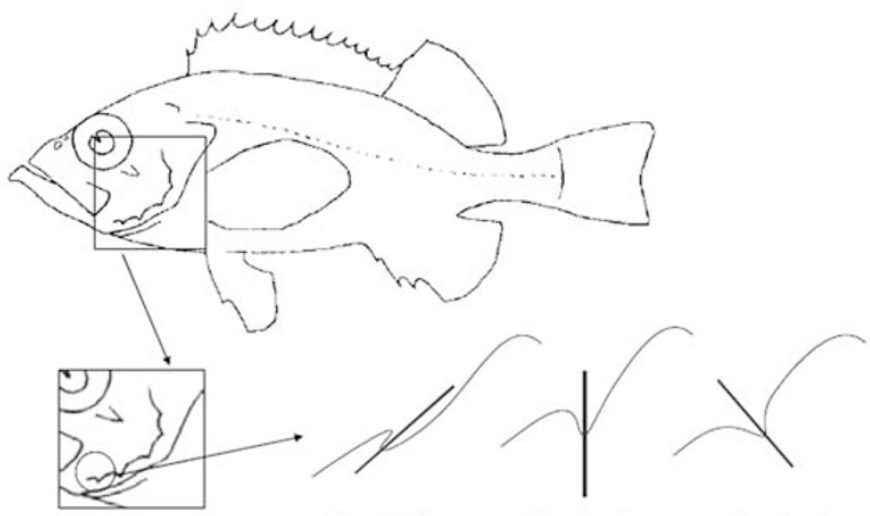

Code 2

Code 3

Code 4

Figure 2 (a) Morphometric measurements, including acronyms used to define distances. (b) Landmarks used in geometric morphometrics. (c) Meristic characters at the position of third (A3S) and fifth (A5S) preopercular spines (redrawn from Ratz et al, 2004).

allelic states (20000 permutations) to compute a new permuted measure, $\rho R_{\mathrm{ST}}$ and 95\% confidence intervals, using the method of Hardy et al. (2003) implemented in SPAGEDI 1.2 (Hardy and Vekemans, 2002). As $\rho R_{\mathrm{ST}}$ approximates to the actual $F_{\mathrm{ST}}$ value, this approach allowed us to test the null hypothesis that $R_{\mathrm{ST}}=\theta_{\mathrm{ST}}$. Under the null hypothesis, it is assumed that differentiation is mainly caused by genetic drift. The alternative hypothesis, $R_{\mathrm{ST}}>\theta_{\mathrm{ST}}$, would suggest that mutations have contributed to genetic differentiation and that the mutation process follows the stepwise mutation model (see Hardy et al., 2003). This would indicate long-term isolation of populations.
To further elucidate evolutionary history, time of divergence was approximated as described by Reusch et al. (2001), using the sampling equation developed by Jin and Chakraborty (1995). This is based on the principle that multi-locus $F_{\mathrm{ST}}$ assuming complete isolation (absence of gene flow) is a function of time (generations), effective population size $N_{\mathrm{e}}$, number of subpopulations and heterozygosity $\left(H_{\mathrm{o}}\right.$ averaged across subpopulations).

$N_{\mathrm{e}}$ was calculated under the infinite allele model by the equation $N_{\mathrm{e}=}\left(H_{\mathrm{o}} /\left(1-H_{\mathrm{o}}\right)\right) 4 \mu^{-1} \quad$ (Crow and Kimura, 1970). Assuming a mutation rate $\mu=10^{-4}$, overall $N_{\mathrm{e}}$ varied from 44920 to 291617 individuals. 
Time of divergence was estimated by comparing the evolution of the predicted value of $F_{\mathrm{ST}}$ to $2 t N_{\mathrm{e}}$, where $t$ is the number of generations (see Reusch et al., 2001), that is, by assessing the value of $t$ required to reach equilibrium $F_{\mathrm{ST}}$ in the absence of gene flow.

Unadjusted $P$-values are reported and significance levels for multiple tests are adjusted using sequential Bonferroni corrections (Rice, 1989). All genetic analyses assume that the microsatellite loci screened were free from the influence of selection. To test this assumption, we investigated whether certain loci might be subject to selection, using the method of Beaumont and Nichols (1996). The test was carried out at different depths (samples for depth zones pooled). Weir and Cockerham's (1984) $\theta$ estimator of $F_{\mathrm{ST}}$ was calculated for each locus, and coalescent simulations $\left(2 \times 10^{6}\right.$ iterations $)$ were then used to generate a distribution of $\theta$ close to the observed distribution. The simulated distribution was used to estimate the probability that specific loci are outliers and therefore, possibly under the influence of selection.

\section{Data analysis: morphology, geometric morphometrics and meristics}

Burnaby's method for size adjustment (Burnaby, 1966) was applied to correct for size variation and to facilitate further analysis without allometric bias (Rohlf and Bookstein, 1987). This method consists of projecting data onto the hyperplane orthogonal to a specified size vector; in this case, the first principal component eigenvector of the general data matrix. To remove allometric size-dependent shape variation, the data were log-transformed before projection (Bookstein et al., 1985; Rohlf and Bookstein, 1987). To examine the effectiveness of the size adjustments, each adjusted variable was regressed on standard length (Zar, 1999). Normality of distributions and homogeneity of variance among groups were tested using the Kolmogorov-Smirnov test (Zar, 1999) and Levene's $\mathrm{F}$ test (Brown and Forsythe, 1974), respectively. Then, data matrices of size-free residuals can be used in further ordination routines. Geometric morphometrics analysis was based on 12 peripheral landmarks (Figure 2b). Size variation was removed before analysis of shape variation, which is then described using a thin-plate spline function to map the deformation in shape of one specimen relative to another (Bookstein, 1991). Landmark coordinates were weighted against a consensus for the whole data set and corresponding weight matrix calculated using the software TpsRewl version 1.45 (Copyright 2007, F James Rohlf, Ecol Evol, SUNY at Sony Brook). A weight matrix, including a uniform component of each individual, was used in further analysis.

To examine morphological differentiation between depth zones, multivariate discriminant function analysis was carried out on the size-adjusted morphology data and the geometric morphometrics weight matrix. The Kruskal-Wallis $\mathrm{H}$ nonparametric analysis of variance (Zar, 1999) was used to examine for differences in meristic (quantitative) characters between depth zones. To evaluate the discrimination power of each meristic character, $P$-values were combined using the 'omnibus' technique (Fisher, 1954).

\section{Results}

\section{Marker neutrality}

Results from coalescent simulations (Beaumont and Nichols, 1996) showed that the joint distributions of $F_{\mathrm{ST}}$ and $\mathrm{H}_{\mathrm{O}}$ values for all nine loci did not differ significantly from those expected under neutral expectations (Supplementary Appendix S4, see Supplementary material). Thus, there was no evidence of either balancing selection or directional selection associated with depth at any of the loci used in the current study.

\section{Spatial correlation of genotypes: depth and geography}

Both Bayesian-based methods partitioned S. mentella into two main clusters in the Irminger Sea (Supplementary Appendix S5, see Supplementary material and Table 1). When the distribution of individual admixture proportions $(q)$ (from STRUCTURE) was examined, the two clusters segregated according to catch depth (shallow and deep). Individual $q$ values were highly significantly different between shallow- and deep-mesopelagic-zones $\left(U_{588,1303}=65292.5, P \ll 0.001\right.$, Mann-Whitney $U$-nonparametric test; Figure 3a). Although the distribution of $q$ values in relation to geographical distance formed two clusters, these overlapped for the major part of the distribution indicating no clear geographic segregation of admixture proportions (Figure $3 \mathrm{~b}$ ). For all samples except one (17), the mean proportion of individual assignment into the two clusters was clear. The shallow-mesopelagic-zone samples assigned poorly $(q<0.3)$ into the cluster containing the deep-zone samples (mean $q>0.7$; Table 2). Although the general trend of two clusters is clear, the analysis also showed some admixture between the clusters that could indicate the presence of hybrids (Figure 3). Sample-based analyses showed that there were no departures from HWE at any loci (Supplementary Appendix S6, see Supplementary material). An AMOVA across-depth zones showed that a small but significant portion of the variation was attributed to the among-depth zones variance component for both $F$-statistics (1.83\%, $P<0.00001)$ and $R$-statistics (3.72\%, $P<0.00001$; Table 3).

Tests for homogeneity of allele frequencies, using exact tests, showed very highly significant $(P<0.00001)$ variation for all loci except Sal1 $(P<0.003)$ and SEB33 $(P=0.18413)$. Similar trends were observed when genotypic distribution was examined across samples (data not shown). However, the overall $F_{\mathrm{ST}}$ value across the Irminger Sea was $0.009(P<0.00001)$. Thus, none of the 153 pairwise comparisons of $F_{\mathrm{ST}}$ values between shallow-mesopelagic samples were significant. Of the 36 pairwise comparisons among deep-mesopelagic samples, only four were significant, with sample number 17

Table 1 The partitioning of 27 S. mentella samples from the Irminger Sea using the program BAPS (Corander et al., 2003, 2004). Maximum posterior probability $(P(S)$ data $)=1000)$

\begin{tabular}{ll}
\hline Cluster (depth zone) & Sample number \\
\hline 1 (Shallow-mesopelagic zone) & $1,2,3,4,5,6,7,8,9,10,11$, \\
& $12,13,14,15,16,17,24,25$ \\
2 (Deep-mesopelagic zone) & $18,19,20,21,22,23,26,27$
\end{tabular}


a Deep zone Shallow zone component component
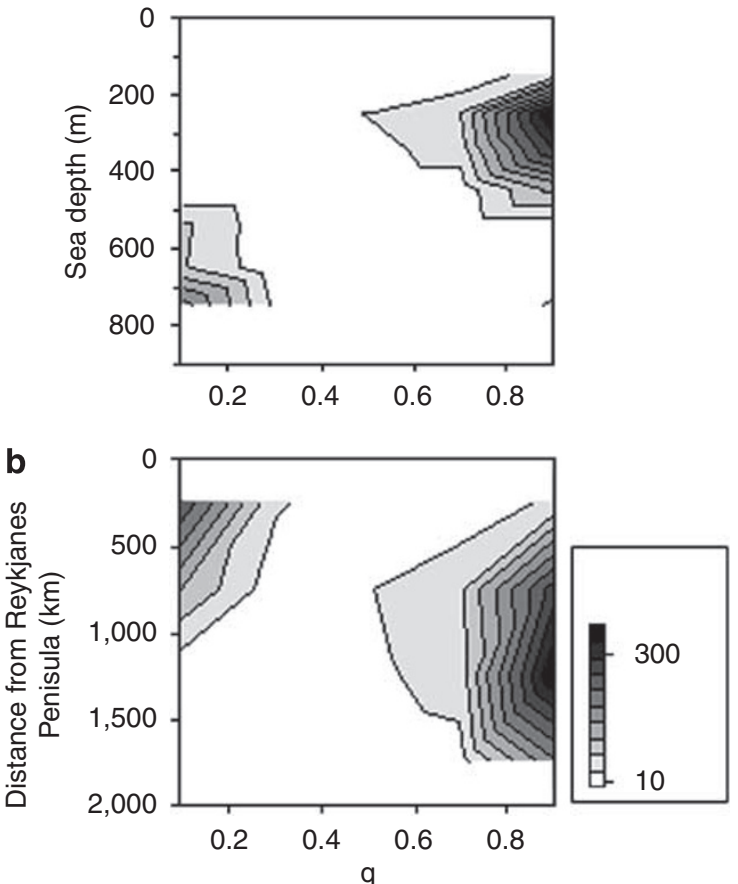

Figure 3 . Contour plot representing the distribution of $q$ (individual admixture proportions) values with (a) depth (m) in the Irminger Sea and (b) distance $(\mathrm{km})$ from the south-west tip of the Reykjanes Peninsula. All S. mentella samples from the Irminger Sea shallow- and deep-mesopelagic-zones were included (1901 individuals). Both figures represent two-dimensional space where the individual's position is determined by $q$ on the $\mathrm{X}$-axis and spatial distance on the Y-axis. Contours indicate the number of individuals in each part of this two-dimensional space. A $q$ value of zero would represent a 'pure' deep-mesopelagic sample, whereas a $q$ value of one, a 'pure' shallow-mesopelagic sample. The scale bar indicates the number of individuals. Comparison across the $550 \mathrm{~m}$ depth zone in (a) showed very highly significant difference between the depth zones of the Irminger Sea $\left(U_{588,1303}=65292.5, P<<0.001\right.$, Mann-Whitney $U$-non-parametric test; Sokal and Rohlf, 1981).

involved in all cases. In contrast, a total of 162 comparisons were carried out between shallow- and deep-mesopelagic samples, of which 141 were significant. Of the remaining 21, 18 involved sample number 17. Multidimensional scaling based on pairwise $F_{\mathrm{ST}}$ values showed a distinct difference between samples drawn from different depth zones (Figure 4). Higher variation was obtained between-depth zones (Dimension 1) than within-depth zones (Dimension 2). Moreover, mean allelic richness was significantly higher for the deepmesopelagic samples $(r=10.940$, s.d. $=3.879)$ than for the shallow-mesopelagic samples $(r=9.672$, s.d. $=3.704$; $P<0.00007)$.

\section{Temporal dimension}

AMOVA showed no variation attributable to the among years variance, indicating temporal stability withindepth zones (Table 3). In addition, the samples from 1996 to 1995 from shallow- and deep-mesopelagic-zones grouped with the recent samples from the same zones (Figure 3; Tables 1 and 2 and Supplementary appendix
Table 2 Admixture analysis for the two clusters identified by the programs STRUCTURE and BAPS, as assigned to the deepmesopelagic-zone cluster. Mean admixture proportions $(q)$ and standard deviation (s.d.) are given for 27 samples of S. mentella from the Irminger Sea

\begin{tabular}{|c|c|c|c|c|}
\hline \multirow[t]{2}{*}{ Sample number } & \multicolumn{2}{|c|}{ STRUCTURE } & \multicolumn{2}{|c|}{$B A P S$} \\
\hline & Mean $q$ & s.d. & Mean q & s.d. \\
\hline \multicolumn{5}{|c|}{ Shallow-mesopelagic zone } \\
\hline 1 & 0.238 & 0.238 & 0.110 & 0.18 \\
\hline 2 & 0.212 & 0.197 & 0.086 & 0.15 \\
\hline 3 & 0.235 & 0.203 & 0.107 & 0.16 \\
\hline 4 & 0.274 & 0.243 & 0.116 & 0.18 \\
\hline 5 & 0.282 & 0.264 & 0.162 & 0.24 \\
\hline 6 & 0.282 & 0.262 & 0.164 & 0.26 \\
\hline 7 & 0.253 & 0.260 & 0.129 & 0.21 \\
\hline 8 & 0.279 & 0.256 & 0.145 & 0.24 \\
\hline 9 & 0.250 & 0.237 & 0.112 & 0.18 \\
\hline 10 & 0.221 & 0.247 & 0.111 & 0.21 \\
\hline 11 & 0.238 & 0.239 & 0.122 & 0.23 \\
\hline 12 & 0.237 & 0.222 & 0.101 & 0.18 \\
\hline 13 & 0.207 & 0.213 & 0.083 & 0.15 \\
\hline 14 & 0.250 & 0.247 & 0.110 & 0.18 \\
\hline 15 & 0.241 & 0.251 & 0.117 & 0.19 \\
\hline 16 & 0.206 & 0.201 & 0.078 & 0.13 \\
\hline \multicolumn{5}{|c|}{ Deep-mesopelagic zone } \\
\hline 17 & 0.475 & 0.355 & 0.346 & 0.38 \\
\hline 18 & 0.728 & 0.339 & 0.696 & 0.37 \\
\hline 19 & 0.838 & 0.203 & 0.825 & 0.26 \\
\hline 20 & 0.844 & 0.194 & 0.819 & 0.25 \\
\hline 21 & 0.818 & 0.251 & 0.801 & 0.30 \\
\hline 22 & 0.863 & 0.188 & 0.851 & 0.24 \\
\hline 23 & 0.803 & 0.255 & 0.785 & 0.32 \\
\hline
\end{tabular}

Archive samples

Shallow-mesopelagic zone

$\begin{array}{lllll}24 & 0.271 & 0.229 & 0.148 & 0.222 \\ 25 & 0.203 & 0.195 & 0.077 & 0.148\end{array}$

Deep-mesopelagic zone

\begin{tabular}{lllll}
26 & 0.838 & 0.233 & 0.818 & 0.289 \\
27 & 0.864 & 0.211 & 0.848 & 0.247 \\
\hline
\end{tabular}

The programs STRUCTURE (Pritchard et al., 2000) and BAPS (Corander and Marttinen, 2006) were used to estimate individual $q$ 's, that is, the estimated proportion of an individual's genotype originating from one or the other of the two populations of origin.

S5, see Supplementary material). The multilocus $R_{\mathrm{ST}}$ value between pooled shallow- and deep-mesopelagic samples was larger than the upper $95 \%$ confidence interval of the permuted $\rho R_{\mathrm{ST}}$ estimate $(P=0.004$; Supplementary Appendix S7, see Supplementary material). This indicates that drift alone cannot explain the observed variation and that there must be a mutational component. Although significant $(P<0.01)$ in only two cases, $R_{\mathrm{ST}}$ values were higher than $\rho R_{\mathrm{ST}}$ estimates at six of nine loci. The fact that $R_{\mathrm{ST}}>\rho R_{\mathrm{ST}}$ for redfish within the Irminger Sea indicates that historical isolation could have played a role in driving the observed pattern of genetic structuring.

A comparison of the expected $F_{\mathrm{ST}}$ as a function of generations $(2 t \mathrm{Ne})$ shows that 900 generations would be sufficient to reach the observed $F_{\mathrm{ST}}$ of 0.009 . Based on a generation time of 30 years (see Magnússon and Magnússon, 1995), the time of divergence is estimated to have been $\sim 27 \mathrm{kyr}$ BP. This suggests that the origin of the genetic variation could have been during the late Pleistocene and that the two gene pools could have 
Table 3 Hierarchical analysis of molecular variance of the influence of depth (among depth zones) and temporal (within depth zones among years) dimensions for 27 samples of $S$. mentella from the Irminger Sea

\begin{tabular}{|c|c|c|c|c|c|c|}
\hline Variance component & $\begin{array}{l}\text { Percentage of variation } \\
\qquad F_{S T}\end{array}$ & $\begin{array}{l}\Phi \text {-Statistics } \\
\text { based }\end{array}$ & $\mathrm{P}^{\mathrm{a}}$ & $\begin{array}{l}\text { Percentage of variation } \\
\qquad R_{S T}\end{array}$ & $\begin{array}{l}\Phi \text {-Statistics } \\
\text { based }\end{array}$ & $\mathrm{P}^{\mathrm{a}}$ \\
\hline \multicolumn{7}{|l|}{ Depth dimension ${ }^{\mathrm{b}}$} \\
\hline Among depth zones & 1.83 & 0.01834 & $<0.00001$ & 3.72 & 0.03716 & $<0.00001$ \\
\hline Among samples within depth zones & -0.49 & -0.00496 & 0.03109 & -0.48 & -0.00496 & $<0.00001$ \\
\hline Within samples & 98.65 & 0.01346 & $<0.00001$ & 96.76 & 0.03237 & $<0.00001$ \\
\hline \multicolumn{7}{|l|}{ Temporal dimension } \\
\hline \multicolumn{7}{|l|}{ Shallow-mesopelagic zone } \\
\hline Among years & 0.08 & 0.00083 & 0.25030 & -0.13 & -0.00129 & 0.76901 \\
\hline Among samples within years & -0.73 & -0.00728 & 1.00000 & -0.52 & -0.00524 & 1.00000 \\
\hline Within samples & 100.64 & -0.00644 & 1.00000 & 100.65 & -0.00653 & 1.00000 \\
\hline \multicolumn{7}{|l|}{ Deep-mesopelagic zone } \\
\hline Among years & -0.31 & -0.00312 & 0.78436 & -0.82 & -0.00823 & 0.88119 \\
\hline Among samples within years & 0.04 & 0.00039 & 0.08990 & 0.17 & 0.00170 & 0.12297 \\
\hline Within samples & 100.27 & -0.00272 & 0.96703 & 100.65 & -0.00651 & 0.91218 \\
\hline
\end{tabular}

Analysis was based on both number of alleles ( $F_{\mathrm{ST}}$ based) and allele sizes $\left(R_{\mathrm{ST}}\right.$ based).

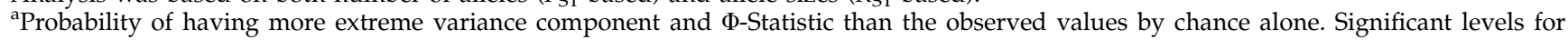
$P$-values: ${ }^{*} \alpha=0.05, P=0.01274 ;{ }^{* *} \alpha=0.01, P=0.0025 ;{ }^{* *} \alpha=0.001, P=0.00025$.

bamples (1-16 and 24-25) vs (17-23 and 26-27).

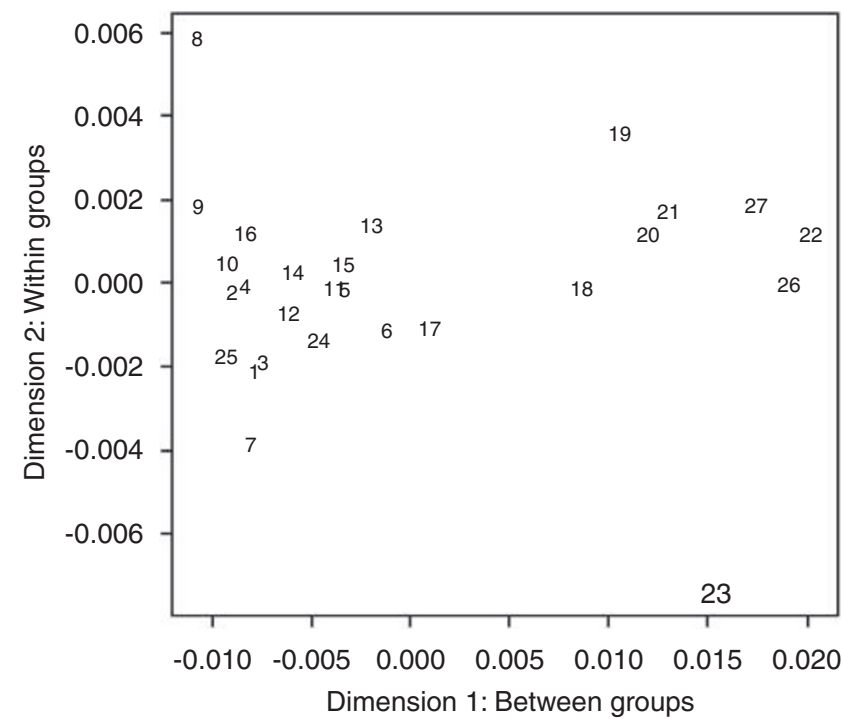

Figure 4 Multidimensional scaling (MDS) figure based on pairwise $F_{\mathrm{ST}}$ values from 27 locations within the Irminger Sea (see Supplementary Appendix S1 in Supplementary material for sample codes).

segregated before the last glacial maximum (18 kyr BP) in the Northern Hemisphere.

Morphology, geometric morphometrics and meristics Multivariate discriminant function analysis (Figure 5a) showed that morphological differences between fish sampled across the depth zones were highly significant (Wilks' $\Lambda=0.849 ; F_{18,672}=6.626 ; P<2 \times 10^{-15}$ ), indicating the existence of two morphotypes within the Irminger Sea. Significant differences between fish from the two depth-zones were found at seven morphological variables out of 18 (Supplementary Appendix S8, see Supplementary material). The importance of these results is highlighted by the fact that the variable $\mathrm{AN}$,

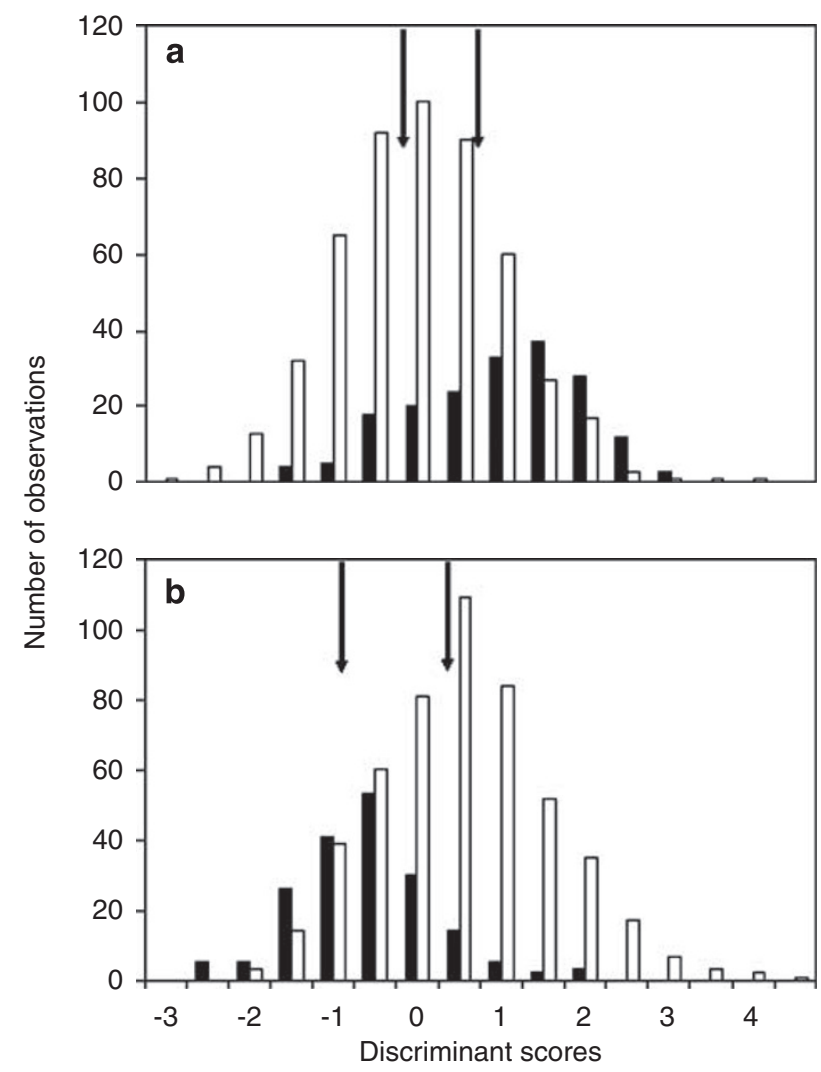

Figure 5 Discriminant analysis of 691 shallow- (black columns) and deep-mesopelagic (white columns) S. mentella from the Irminger Sea (a) based on 18 morphological variables (Wilks' $\Lambda=0.849$; $F_{18,672}=6.626 ; P<1 \times 10^{-15}$ ). (b) Geometric morphometrics based on 12 landmarks (Wilks' $\Lambda=0.795 ; F_{18}, 672=10.738 ; P<1 \times 10^{-26}$ ). Centroids of discriminant scores for each group are indicated by arrows.

which had the highest discriminative power in SaboridoRey and Nedreaas (2000) was not included. Differences in body form based on geometric morphometrics 
(Figure 5b) were more pronounced between depth zones (discriminant function analysis; Wilks' $\Lambda=0.795$; $\left.F_{18,672}=10.738 ; P<1 \times 10^{-26}\right)$ than traditional morphometry method could show.

Differences in meristic characters between depth zones were also highly significant (Fisher's 'omnibus' test (1954); $\left.\chi_{[16]}^{2}=60.065, P<0.001\right)$. Differences in the spine angles of the third and the fifth pre-opercular spines (A3S and A5S) across the depth zones were also tested. For both A3S (Kruskal-Wallis $\mathrm{H}$ test, $H_{1, \mathrm{n}=790}=8.1$, $P<0.005)$ and A5S $\left(H_{1, \mathrm{n}=788}=41.5, P<0.00001\right)$, spines pointed in a more forward direction in deep-mesopelagic specimens, compared with those from the shallowmesopelagic area (Supplementary Appendix S9, see Supplementary material). Size distribution of the two morphs is given in Supplementary Appendix S10 (see Supplementary material).

\section{Discussion}

\section{Genetic differentiation}

Our results showed a clear segregation of two gene pools of the pelagic $S$. mentella in the Irminger Sea and support earlier findings (for example, Johansen et al., 2000; Roques et al., 2002; Joensen and Grahl-Nielsen, 2004; Stefánsson and Pampoulie, 2006; Stefánsson et al., 2004, 2006). Bayesian-based methods (Supplementary Appendix S5, see Supplementary material and Table 1) were supported by the more traditional approaches such as the pairwise comparison plotted in Figure 4. Individual assignment values ( $q$ proportions, Table 2 ) show that the Bayesian methods were able to efficiently classify individuals with no geographical or depth information.

\section{Speciation that began in allopatry during the last glaciation}

Analyses of pelagic S. mentella genotypes allowed us to determine patterns of genetic structure and diversity across the Irminger Sea. These results suggested the presence of a historical signal in the current data. Evidence for this comes from three different analyses. First, the hierarchical AMOVA based on the stepwise mutation model (allelic size) showed that twice as much variation was attributed between depth groups $(3.72 \%)$ than when the analysis was based on the infinite allele model (allelic identity, 1.83\%). This indicates that a mutational component contributes a similar amount of variation (1.89\%) among the depth zones to the drift component. Second, another comparison of the two components (see Supplementary Appendix S7, see Supplementary material) shows that mutational signal obtained was statistically significant, suggesting a major role of mutation in the observed genetic variation between the two gene pools. Finally, estimates for the time of divergence $(\sim 27 \mathrm{kyr} \mathrm{BP})$ indicated that the two gene pools probably segregated in allopatry before the last glacial maximum (18 kyr BP) and before post-glacial recolonization of the Irminger Sea (7-8 kyr BP).

Speciation may involve different geographical phases. Commonly in animals it begins with an allopatric phase and as geographical barriers breakdown, the incipient species undergo secondary contact resulting in parapatry (or sympatry) (Schluter, 2001; Rundle and Schluter, 2004; Rundle and Nosil, 2005). Allopatric speciation begins when a single panmictic population is divided into components by natural events such as elevation of land bridges, formation of mountains, continental drift, climatic change, glaciation and so on (Orr and Smith, 1998). At the last glacial maximum the sea ice limit reached south of Iceland (Siegert and Dowdeswell, 2004), forcing fish into a glacial refuge in the North Atlantic in more southern latitudes. It has been suggested that a second refuge existed in the North Sea (Benn and Evans, 1998) and a third in the southern Northwest Atlantic (Hardie et al., 2006). Although allopatric speciation is not itself defined as adaptive, there nevertheless is the implication that isolated populations may become adapted to their environments. In this example, two geographically-isolated glacial refuges could have set the stage for local adaptation to different environmental conditions to occur. In addition, genetic drift and the occurrence of different mutations would lead to the accumulation of genetic differences in the absence of gene flow (Dieckmann et al., 2004). In this way, reproductive isolation between the redfish morphotypes could have evolved, or at least been initiated as a byproduct of genetic drift and the pleiotropic effects of adaptation within different glacial refuges (Dobzhansky, 1937). These results, which suggest historical separation, seems to contrast with findings on vermilion rockfish (S. miniatus) in which differentiation arising from loss of ontogenetic depth migration is hypothesized (Hyde et al., 2008).

\section{Possible isolating mechanisms}

Morphological analyses (based both on meristics and geometric morphometrics) support the Magnússon and Magnússon (1995) hypothesis of two pelagic S. mentella phenotypes in the Irminger Sea. These results show that variation in both genetic and morphological markers support the hypothesis of depth segregation of the two morphs.

During postglacial colonisation, the two redfish morphs presumably colonised different depth zones of the Irminger Sea (as reflected in the current distribution of $q$ values in Figure 3). The genetic results indicate that the morphs continue to mate assortatively (for example, Fraser and Bernatchez, 2005). Therefore, the reproductive isolation between the morphs has resisted the homogenizing forces inherent in the pelagic environment. As current results offer no direct evidence of the nature of this reproductive isolation, the scenarios discussed below are hypothetical. As the main mating and the spawning areas of the two morphotypes are separated in space (Magnússon and Magnússon, 1995; ICES, 2005), it is possible that pre-zygotic reproductive isolation could stem from adaptive life-history differentiation among the two incipient species (for example, Avise et al., 1986; Baker et al., 1993; and see Schluter, 2001 and Rundle and Nosil, 2005 for reviews). Evidence of hybridization was seen as variation in the contours in Figure 3 and from results of the admixture analysis (Table 2). For most samples, around $80 \%$ of genotype is estimated to be from one specific gene pool and $20 \%$ from the alternate group, with the exception of sample 17, which suggests secondary contact (Hewitt, 2000; Turgeon and Bernatchez, 2001; Fraser and Bernatchez, 2005) between gene pools that are not completely reproductively isolated. This 
pattern suggests that post-zygotic isolation mechanisms, such as trophic polymorphism (Rice and Hostert, 1993; Skúlason and Smith, 1995; Smith and Skúlason, 1996; ICES, 2002 Supplementary Appendix S11, see Supplementary material) with reduced ecological hybrid fitness (Noor, 1999; Schluter, 2001; Rundle and Nosil, 2005) may be involved in maintaining segregation between the two groups. Contrasting selection pressures on body size within the two refuges during the Pleistocene glaciations could either have resulted in pre-zygotic isolation (for example, Nagel and Schluter, 1998) or post-zygotic isolation (for example, Bolnick et al., 2006) with reinforcement (Noor, 1999; Rundle and Nosil, 2005) in the subsequent parapatric encounter of the two morphs.

\section{Life-cycle hypothesis}

Our results do not support Novikov's et al. (2002) suggestions of one panmictic population in which younger individuals inhabit the shallow-zone, whereas the older ones occupy the deep-zone. Allelic richness was significantly higher in the deep mesopelagic-zone when compared with redfish from the shallow mesopelagic-zone. It is unlikely that greater allelic richness in groups of older fish is the product of natural selection by mortality of younger individuals in one population, as population reductions tend to reduce genetic diversity (Nei et al., 1975). Even though the microsatellites used here occur in the non-coding region of the genome (Jarne and Lagoda, 1996), they could be subject to hitch-hiking selection (for example, Nielsen et al., 2006). However, our results show that this was apparently not the case for any of the markers used in this study. Therefore, our interpretation of $S$. mentella genetic population structure is free of arguments regarding selection acting at specific loci (Ward and Grewe, 1994). In addition, earlier research on the species regarding horizontal population structuring (for example, Roques et al., 2002; Joensen and GrahlNielsen, 2004); structuring based on individuals typed as either oceanic or deep-sea phenotypes (Johansen et al., 2000; Stefánsson et al., 2004; Daníelsdóttir et al., 2008) or depth (Stefánsson and Pampoulie, 2006; Stefánsson et al., 2006) indicate that there are two gene pools within the Irminger Sea. Thus from current and earlier findings, we conclude that the differences between the groups inhabiting the two zones are because of the presence of two gene pools, rather than different stages of the life cycle.

\section{Conclusion}

Current knowledge about the glaciation history of the North Atlantic and the presence of a historical signal in the genetic data suggests that allopatric speciation rather than niche-specific adaptation in parapatry, was involved in the present structure of the Irminger Sea redfish. However, a hybridization signal in the data shows that allopatric separation has not led to complete reproductive isolation. On the other hand, meristic and morphological differences between the two morphs may have resulted from biological isolation between the contemporarily-parapatric incipient species.

\section{Acknowledgements}

The research reported here was carried out under the REDFISH (QLK5-CT1999-01222) project funded by EU's fifth framework. TFC and JC acknowledge funding from the Beaufort Marine Research Award in Fish Population Genetics funded by the Irish Government under the Sea Change programme. We extend their gratitude to B Báraarson, S Guamundsóttir, IF Egilsdóttir, V Chosson and Th Jörundsdóttir for their skilled technical assistance. We thank the crews of both commercial and research vessels for sampling assistance. We also thank Michael M. Hansen of the Danish Institute for Fisheries Research for his contribution to earlier versions of the paper.

\section{References}

Altukhov JUP, Nefyodov GN (1968). A study of blood serum protein composition by agar-gel electrophoresis in types of redfish (genus Sebastes). ICNAF Res Bull 5: 86-90.

Avise JC, Helfman GS, Saunders NC, Hales LS (1986). Mitochondrial DNA differentiation in North Atlantic eels: population genetic consequences of an unusual life history pattern. Proc Natl Acad Sci USA 83: 4350-4354.

Baker CS, Perry A, Bannister JL, Weinrich MT, Abernethy RB, Calambokidis J et al. (1993). Abundant mitochondrial DNA variation and world-wide population structure in humpback whales. Proc Natl Acad Sci USA 90: 8239-8243.

Beaumont MA, Nichols RA (1996). Evaluating loci for use in the genetic analysis of population structure. Proc Natl Acad Sci USA 263: 1619-1626.

Benn DI, Evans JA (1998). Glaciers \& Glaciation. Arnold: London.

Bernatchez L, Dodson JJ (1990). Allopatric origin of sympatric populations of lake whitefish (Coregonus clupeaformis) as revealed by mitochondrial DNA restriction analysis. Evolution 44: 1263-1271.

Bernatchez L, Wilson CC (1998). Comparative phylogeography of nearctic and palearctic freshwater fishes. Mol Ecol 7: 431-452.

Bolnick DI, Near TJ, Wainwright PC (2006). Body size divergence promotes post-zygotic reproductive isolation in centrarchids. Evol Ecol Res 8: 903-913.

Bookstein FL (1991). Morphometric Tools for Landmark Data: Geometry and Biology. Cambridge University Press: New York.

Bookstein FL, Chernoff B, Elder R, Humphries J, Smith G, Strauss R (1985). Morphometrics in Evolutionary Biology. The Geometry of Size and Shape Change, with Examples from Fishes. Academy of Natural Sciences of Philadelphia: Philadelphia.

Brown MB, Forsythe AB (1974). Robust tests for equality of variances. J Am Stat Assoc 69: 364-367.

Burnaby TP (1966). Growth-invariant discriminant functions and generalized distances. Biometrics 22: 96-110.

Corander J, Marttinen P (2006). Bayesian identification of admixture events using multilocus molecular markers. Mol Ecol 15: 2833-2843.

Corander J, Waldmann P, Sillanpaa MJ (2003). Bayesian analysis of genetic differentiation between populations. Genetics 163: 367-374.

Corander J, Waldmann P, Marttinen P, Sillanpaa MJ (2004). BAPS 2: enhanced possibilities for the analysis of genetic population structure. Bioinformatics 20: 2363-2369.

Coyne JA (1992). Genetics and speciation. Nature 355: 511-515.

Crow JF, Kimura M (1970). An introduction to population genetics theory. Harper \& Row: New York.

Daníelsdóttir AK, Gíslason D, Kristinsson K, Stefánsson MÖ, Johansen T, Pampoulie C (2008). Population structure of deep-sea and oceanic phenotypes of deepwater redfish in the Irminger Sea and Icelandic continental slope: are they cryptic species? Trans Am Fish Soc 137: 1723-1740. 
Dieckmann U, Metz JAJ, Doebeli M, Tautz D (2004). Adaptive Speciation. Cambridge University Press, Cambridge.

Dobzhansky TH (1937). Genetics and the Origin of Species. Columbia University Press: New York.

Dushchenko VV (1987). Polymorphism of NADP-dependent malate-dehydrogenase in Sebastes mentella (Scorpaenidae) from the Irminger Sea. J Icht 27: 129-131.

Evanno G, Regnaut S, Goudet J (2005). Detecting the number of clusters of individuals using the software STRUCTURE: a simulation study. Mol Ecol 14: 2611-2620.

Excoffier L, Smouse PE, Quattro JM (1992). Analysis of molecular variance inferred from metric distances among DNA haplotypes: application to human mitochondrial-DNA restriction data. Genetics 131: 479-491.

Excoffier L, Laval G, Schneider S (2005). Arlequin ver. 3.0: an integrated software package for population genetics data analysis. Evol Bioinf Onl 1: 47-50.

Fisher RA (1954). Statistical Methods for Research Workers. Oliver \& Boyd: Edinburgh.

Fraser DJ, Bernatchez L (2005). Allopatric origins of sympatric brook charr populations: colonization history and admixture. Mol Ecol 14: 1497-1509.

Goudet J (1995). Fstat (Version 1.2): a computer program to calculate F-statistics. J Hered 86: 485-486.

Goudet J, Raymond M, Demeeus T, Rousset F (1996). Testing differentiation in diploid populations. Genetics 144: 1933-1940.

Gysels ES, Hellemans B, Pampoulie C, Volckaert FAM (2004a). Phylogeography of the common goby, Pomatoschistus microps, with particular emphasis on the colonization of the Mediterranean and the North Sea. Mol Ecol 13: 403-417.

Gysels ES, Hellemans B, Patarnello T, Volckaert FAM (2004b). Current and historic gene flow of the sand goby Pomatoschistus minutus on the European Continental Shelf and in the Mediterranean Sea. Biol J Linn Soc 83: 561-576.

Hardie DC, Gillett RM, Hutchings JA (2006). The effects of isolation and colonization history on the genetic structure of marine-relict populations of Atlantic cod (Gadus morhua) in the Canadian Arctic. Can I Fish Aquat Sci 63: 1830-1839.

Hardy OJ, Vekemans X (2002). SPAGEDI: a versatile computer program to analyse spatial genetic structure at the individual or population levels. Mol Ecol Notes 2: 618-620.

Hardy OJ, Charbonnel N, Freville H, Heuertz M (2003). Microsatellite allele sizes: a simple test to assess their significance on genetic differentiation. Genetics 163: 1467-1482.

Hewitt GM (1996). Some genetic consequences of ice ages, and their role in divergence and speciation. Biol J Linn Soc 58: 247-276.

Hewitt G (2000). The genetic legacy of the Quaternary ice ages. Nature 405: 907-913.

Hyde JR, Kimbrell CA, Budrick JE, Lynn EA, Vetter D (2008). Cryptic speciation in the vermilion rockfish (Sebastes miniatus) and the role of bathymetry in the speciation process. Mol Ecol 17: 1122-1136.

ICES (2001). Planning Group on Redfish Stocks. ICES CM 2001/ D:04 Ref ACFM

ICES (2002). Planning Group on Redfish Stocks. ICES CM 2002/ D:08 Ref ACFM

ICES (2005). Report of the Study Group on Stock Identity and Management Units of Redfishes. 31 August-3 September 2004; Norway. ICES CM 2005/ACFM:10.

Jarne P, Lagoda PJL (1996). Microsatellites, from molecules to populations and back. Trends Ecol Evol 11: 424-429.

Jin L, Chakraborty R (1995). Population structure, stepwise mutation, and heterozygote deficiency and their implications in DNA forensics. Heredity 74: 274-285.

Joensen H, Grahl-Nielsen O (2004). Stock structure of Sebastes mentella in the North Atlantic revealed by chemometry of the fatty acid profile in heart tissue. ICES J Mar Sci 61: 113-126.

Johansen T, Nedreaas K, Naevdal G (1993). Electrophoretic discrimination of blue mouth, Helicolenus dactylopterus
(De-La-Roche, 1809), from Sebastes spp. in the Northeast Atlantic. Sarsia 78: 25-29.

Johansen T, Danielsdottir AK, Meland K, Naevdal G (2000). Studies of the genetic relationship between deep-sea and oceanic Sebastes mentella in the Irminger Sea. Fish Res 49: 179-192.

Johnson AG, Utter FM, Hodgins HO (1973). Estimate of genetic polymorphism and heterozygosity in 3 species of rockfish (genus Sebastes). Comp Biochem Physiol 44: 397-406.

Jones DH. (1968). Angling for redfish. ICNAF Special Publ 7 (Part 1): 1225-1240.

Kelly DW, Macisaac HJ, Heath DD (2006). Vicariance and dispersal effects on phylogeographic structure and speciation in a widespread estuarine invertebrate. Evolution 60: 257-267.

Knowlton N (1993). Sibling species in the sea. Annu Rev Ecol Syst 24: 189-216.

Lessios HA (1981). Divergence in allopatry: molecular and morphological differentiation between sea urchins separated by the Isthmus of Panama. Evolution 35: 618-634.

Luchetti A, Marini M, Mantovani B (2005). Mitochondrial evolutionary rate and speciation in termites: data on European Reticulitermes taxa (Isoptera, Rhinotermitidae). Insect Soc 52: 218-221.

Magnússon J (1972). Tilraunir til karfaveida med midsjávarvörpu í úthafinu. Aegir 65: 430-432.

Magnússon J, Magnússon JV (1995). Oceanic redfish (Sebastes mentella) in the Irminger Sea and adjacent waters. Sci Mar 59: 241-254.

Miller KM, Schulze AD, Withler RE (2000). Characterization of microsatellite loci in Sebastes alutus and their conservation in congeneric rockfish species. Mol Ecol 9: 240-242.

Naevdal G (1978). Differentiation between 'marinus' and 'mentella' types of redfish by electrophoresis of haemoglobins. Fiskdir Skr Ser Havunders 16: 359-368.

Nagel L, Schluter D (1998). Body size, natural selection, and speciation in sticklebacks. Evolution 52: 209-218.

Nedreaas K, Naevdal G (1989). Studies of Northeast Atlantic species of redfish (genus Sebastes) by protein polymorphism. J Conseil 46: 76-93.

Nedreaas K, Naevdal G (1991a). Identification of 0-Group and 1-group redfish (genus Sebastes) using electrophoresis. ICES J Mar Sci 48: 91-99.

Nedreaas K, Naevdal G (1991b). Genetic studies of redfish (Sebastes spp.) along the continental slopes from Norway to East Greenland. ICES J Mar Sci 48: 173-186.

Nedreaas K, Johansen T, Naevdal G (1994). Genetic studies of redfish (Sebastes spp.) from Icelandic and Greenland waters. ICES J Mar Sci 51: 461-467.

Nefyodov GN (1971). Serum haptoglobins in the marinus and mentella types of North Atlantic redfish. Rapp Réun Cons Inter Expl Mer 161: 126-129.

Nei M, Maruyama T, Chakraborty R (1975). Bottleneck effect and genetic-variability in populations. Evolution 29: 1-10.

Nielsen EE, Hansen MM, Meldrup D (2006). Evidence of microsatellite hitch-hiking selection in Atlantic cod (Gadus morhua L.): implications for inferring population structure in nonmodel organisms. Mol Ecol 15: 3219-3229.

Noor MAF (1999). Reinforcement and other consequences of sympatry. Heredity 83: 503-508.

Novikov GG, Stroganov AN, Afanasjev KI (2002). Analysis of population and genetics characteristics of redfish of the Irminger Sea. ICES WD no. 19.

Orr MR, Smith TB (1998). Ecology and speciation. Trends Ecol Evol 13: 502-506.

Pampoulie C, Daníelsdóttir AK (2008). Resolving species identification problems in the genus Sebastes using nuclear genetic markers. Fish Res 93: 54-63.

Pampoulie C, Stefánsson MÖ, Danilowicz BS, Daníelsdóttir AK (2008). Recolonisation history and large scale dispersal in the 
open sea: the case study of the North Atlantic Cod (Gadus morhua L.). Biol J Linn Soc 94: 315-329.

Pritchard JK, Stephens M, Donnelly P (2000). Inference of population structure using multilocus genotype data. Genetics 155: 945-959.

Ratz HJ, Saborido-Rey JF, Sigurdsson Th, Dalen J, Naevdal G (2004). Population structure, reproductive strategies and demography of redfish (Genus Sebastes) in the Irminger Sea and adjacent waters. Quality of Life and Management of Living Resources Key Action 5: Sustainable Agriculture, Fisheries and Forestry. QLK5-CT1999-01222.

Raymond M, Rousset F (1995a). Genepop (version-1.2)population genetics software for exact tests and ecumenicism. J Hered 86: 248-249.

Raymond M, Rousset F (1995b). An exact test for population differentiation. Evolution 49: 1280-1283.

Reusch TBH, Wegner KM, Kalbe M 2001)). Rapid genetic divergence in postglacial populations of threespine stickleback (Gasterosteus aculeatus): the role of habitat type, drainage and geographical proximity. Mol Ecol 10: 2435-2445.

Ribera I, Vogler AP (2004). Speciation of Iberian diving beetles in Pleistocene refugia (Coleoptera, Dytiscidae). Mol Ecol 13: 179-193.

Rice WR (1989). Analyzing tables of statistical tests. Evolution 43: 223-225.

Rice WR, Hostert EE (1993). Laboratory experiments on speciation: what have we learned in 40 years. Evolution 47: 1637-1653.

Rohlf FJ, Bookstein FL (1987). A comment on shearing as a method for size correction. Syst Zool 36: 356-367.

Roques S, Duchesne P, Bernatchez L (1999a). Potential of microsatellites for individual assignment: the North Atlantic redfish (genus Sebastes) species complex as a case study. Mol Ecol 8: 1703-1717.

Roques S, Pallotta D, Sevigny JM, Bernatchez L (1999b). Isolation and characterization of polymorphic microsatellite markers in the North Atlantic redfish (Teleostei: Scorpaenidae, genus Sebastes). Mol Ecol 8: 685-687.

Roques S, Sevigny JM, Bernatchez L (2002). Genetic structure of deep-water redfish, Sebastes mentella, populations across the North Atlantic. Mar Biol 140: 297-307.

Ross I, Gentleman R (1996). R: A language for data analysis and graphics. J Comp Graph Stat 5: 299-314.

Rundle HD, Schluter D (2004). Natural selection and ecological speciation in sticklebacks. In: Dieckmann U, Doebeli M, Metz JAJ, Tautz D (eds). Adaptive Speciation. Cambridge University Press: Cambridge. pp 192-209.

Rundle HD, Nosil P (2005). Ecological speciation. Ecol Lett 8: 336-352.
Saborido-Rey F, Nedreaas KH (2000). Geographic variation of Sebastes mentella in the Northeast Arctic derived from a morphometric approach. ICES J Mar Sci 57: 965-975.

Sakharov GP (1964). Redfish above the ocean depths. ICNAF RES Bull 1: 39-42.

Sambrook J, Russell DW (2001). Molecular Cloning: a Laboratory Manual. Cold Spring Harbour Laboratory Press: New York.

Schluter D (2001). Ecology and the origin of species. Trends Ecol Evol 16: 372-380.

Siegert MJ, Dowdeswell JA (2004). Numerical reconstructions of the Eurasian Ice Sheet and climate during the Late Weichselian. Quat Sci Rev 23: 1273-1283.

Skúlason S, Smith TB (1995). Resource polymorphisms in vertebrates. Trends Ecol Evol 10: 366-370.

Smith TB, Skúlason S (1996). Evolutionary significance of resource polymorphisms in fishes, amphibians, and birds. Annu Rev Ecol Syst 27: 111-133.

Sokal RR, Rohlf FJ (1981). Biometry. W.H. Freeman and Company: New York

Stefánsson MO, Pampoulie C (2006). The influence of depth in fishery management: evidence from redfish (Sebastes mentella) and cod (Gadus morhua). J Fish Biol Suppl C 69: 256.

Stefánsson MÖ, Gislason D, Thorgilsson B, Ragnarsdóttir A, Daníelsdótttir AK, Sigurdsson Th (2004). Population structure of S. mentella within and around the Irminger Sea. Working document to the Study Group on Stock Identity and Management Units of Redfishes. ICES CM 2003/ACFM WD no. 7 .

Stefánsson MO, Pampoulie C, Thorgilsson B, Ragnarsdottir A, Gislason D, Danielsdottir AK et al. (2006). Natural selection and adaptation of the deep-sea redfish Sebastes mentella. J Fish Biol Suppl C 69: 235.

Taaning AV (1949). On the breeding places and abundance of the redfish (Sebastes) in the North Atlantic. J Cons Inter Expl Mer XVI: 85-95.

Turgeon J, Bernatchez L (2001). Clinal variation at microsatellite loci reveals historical secondary intergradation between glacial races of Coregonus artedi (Teleostei: Coregoninae). Evolution 55: 2274-2286.

Walsh PS, Metzger DA, Higuchi R (1991). Chelex-100 as a medium for simple extraction of DNA for PCR-based typing from forensic material. Biotechniques 10: 506-513.

Ward RD, Grewe PM (1994). Appraisal of molecular-genetic techniques in fisheries. Rev Fish Biol Fish 4: 300-325.

Weir BS, Cockerham CC (1984). Estimating F-Statistics for the analysis of population-structure. Evolution 38: 1358-1370.

Zar JH (1999). Biostatistical Analysis. Prentice-Hall Inc.: New Jersey.

Supplementary information accompanies the paper on Heredity website (http://www.nature.com/hdy) 